\title{
DEVELOPMENT OF A VALIDATED METHOD FOR SIMULTANEOUS QUANTIFICATION OF CLARITHROMYCIN AND LEVOFLOXACIN BY HIGH-PERFORMANCE LIQUID CHROMATOGRAPHY-DIODE ARRAY DETECTOR
}

\author{
QAZI AMIR IJAZ1*, NASIR ABBAS ${ }^{1}$, SUMERA LATIF², AMJAD HUSSAIN ${ }^{1}$, \\ MUHAMMAD SOHAIL ARSHAD ${ }^{3}$, EJAZ ALI ${ }^{1}$, MEMOONA RASHID', \\ KASHIF SOHAIL ${ }^{4}$, SOHAIL RIAZ ${ }^{4}$ and NADEEM IRFAN BUKHARI ${ }^{1}$ \\ ${ }^{1}$ University College of Pharmacy, University of the Punjab, Lahore, Pakistan \\ ${ }^{2}$ Institute of Pharmacy, Faculty of Pharmaceutical and Allied Health Sciences, \\ Lahore College for Women University, Lahore, Pakistan \\ ${ }^{3}$ Department of Pharmaceutics, Bahauddin Zakariya University, Multan, Pakistan \\ ${ }^{4}$ Akson College of Pharmacy, Mirpur University of Science and Technology, \\ Mirpur AJ \& K, Pakistan
}

\begin{abstract}
This study aims at the development of a validated reverse phase-high performance liquid chromatography (RP-HPLC) method for the simultaneous quantification of levofloxacin (LVX) and clarithromycin (CAM). Eclipse X DB C18 column $(5 \mu \mathrm{m}, 4.6 \times 250 \mathrm{~mm})$ was used as a stationary phase, and monobasic potassium phosphate $\left(\mathrm{KH}_{2} \mathrm{PO}_{4}\right)$ buffer $(0.035 \mathrm{M})$ : acetonitrile $(75: 25)$ was used as an isocratic mobile phase. The $\mathrm{pH}$ of the mobile phase was adjusted to 4.5 with the help of diluted orthophosphoric acid. The diode array detector (DAD) was operated at $205 \mathrm{~nm}$ and $294 \mathrm{~nm}$ for the detection of CAM and LVX, respectively. Limit of detection (LOD) values for CAM and LVX were $1.22 \mu \mathrm{g} / \mathrm{mL}$ and $0.79 \mu \mathrm{g} / \mathrm{mL}$, respectively. Limit of quantification (LOQ) values for CAM and LVX were $4.08 \mu \mathrm{g} / \mathrm{mL}$ and $2.64 \mu \mathrm{g} / \mathrm{mL}$, respectively. The method was precise as $\%$ relative standard deviation (\% RSD) values were less than $2 \%$ for all types of precision. This method was successfully applied to determine the percentage contents of both drugs in the pharmaceutical preparation.
\end{abstract}

Keywords: clarithromycin, levofloxacin, high-performance liquid chromatography, diode array detector, validation, simultaneous quantification

Simultaneous estimation is often desirable for the detection and quantification of drugs in multiple drug formulations. For the multi-component analysis, various techniques such as spectrophotometry (UV-VIS, IR, MS) and chromatography (HPLC, TLC) are used. Among these techniques, high-performance liquid chromatography (HPLC) is one of the most commonly used for this purpose (1). Rapid quantification, robustness, selectivity, and best quality results with minimum errors are some of the trademarks of HPLC, which make it a consistent analytical technique for the quality control of pharmaceuticals (2). HPLC can be classified based on the mode of separation, e.g. reverse phase (RP) and normal phase (NP) separation. Depending on the nature of the drug, several types of detectors can be used in HPLC such as UV/Visible, diode array, electrochemical and fluorescent detector (3). RP-HPLC when combined with a diode array detector (DAD) is a simple and most reliable system which provides an excellent opportunity to quantify more than one active pharmaceutical ingredient (API) by detecting them at their respective wavelengths (4).

Antibiotics are often used in combination to treat various infectious diseases such as tuberculosis, community-acquired pneumonia, and Helicobacter pylori - induced gastric ulcers. In these cases, combination therapy can provide an additive or synergistic effect, demonstrating broad spectra antibacterial activities in mixed infections which results in a better therapeutic outcome and reduced chances of resistance development (5). Such an antibiotic com-

\footnotetext{
* Corresponding author: e-mail: amir.akson@must.edu.pk
} 
bination used routinely in clinical practice is levofloxacin (LVX) and clarithromycin (CAM). This antibiotic combination showed good bactericidal and synergistic effect against $H$. pylori, when tested on the population of Taiwan (6). Similarly, when studied against Legionella pneumophila isolates, this combination also revealed a synergistic effect (7).

LVX (Fig. 1A), one of the most commonly used fluoroquinolone antibacterial is an active Lisomer isolated from the racemic mixture of ofloxacin. It possesses wide spectrum activity against both Gram-positive and Gram-negative microbes $(8,9)$. Excellent antibacterial activity and low frequency of adverse effects make LVX an ideal drug candidate against infections such as community-acquired pneumonia and chronic bronchitis (10). CAM (Fig. 1B) (6-O-methylerythromycin) is a semi-synthetic macrolide antibiotic with a wide antibacterial spectrum. As compared to erythromycin, CAM possesses several advantages such as better gastric stability and systemic drug absorption. Streptococci and staphylococci bacteria are more susceptible to CAM as compared to erythromycin (11). It is commonly used against communityacquired pneumonia, superficial infections, leprosy, opportunistic mycobacterial infections, and H. pylori induced ulcers (12).

Several methods have been reported for the quantitative determination of CAM and LVX separately, but no method is available yet for the quantification of these two drugs simultaneously (13-15). As a part of the fabrication of a 3D printed bilayer tablet of CAM and LVX, the development of a suitable assay method for the simultaneous estimation of both drugs is a prerequisite (16-18). Therefore, the objective of this study was to develop a simple, precise, rapid, and sensitive method for the simulta- neous quantification of LVX and CAM by RPHPLC-DAD. The developed method was applied to simultaneously quantify both drugs in pharmaceutical preparation.

\section{EXPERIMENTAL}

\section{Chemicals}

HPLC grade methanol (Duksan, Korea), acetonitrile (Tedia, USA), monobasic potassium phosphate, orthophosphoric acid, and acetic acid were purchased from Sigma Aldrich, USA. CAM and LVX were obtained as a kind gift from Akson Pharmaceuticals, Mirpur AJ\&K, Pakistan.

\section{Equipment}

HPLC system (1200 Series, Agilent Technologies, Germany) equipped with isocratic pump (G1310/A), degasser (G-1379/A), column thermostat (G-1316/A), autosampler (G-1329/A), fluorescence detector (G-1321/A), diode array detector (DAD) (G-1312/A) and chem station LC/LCMS for Windows. Reverse Phase (RP) column Eclipse X DB C18 $(5 \mu \mathrm{m}, 4.6 \times 250 \mathrm{~mm})$ was used. Other instruments included oven (U10 Memmert, Germany), pH Meter (Hanna, Romania), Ultra-sonic water bath (Branson, USA), and digital vortex mixer (Thermo scientific, USA). Polytetrafluoroethylene membrane syringe filters $(0.22 \mu \mathrm{m}$ Minisart SRP15, Germany) and nylon-H filters (0.22 $\mu \mathrm{m}$ Sterlitech, USA) were used.

\section{Method development \\ Preparation of standard solutions}

The combined standard stock solution of LVX $(500 \mu \mathrm{g} / \mathrm{mL})$ and CAM $(1000 \mu \mathrm{g} / \mathrm{mL})$ was prepared in $0.1 \%$ acetic acid. The stock solution was diluted with the mobile phase to prepare working standard
A<smiles>C[C@H]1COc2c(N3CCN(C)CC3)c(F)cc3c(=O)c(C(=O)O)cn1c23</smiles>

B

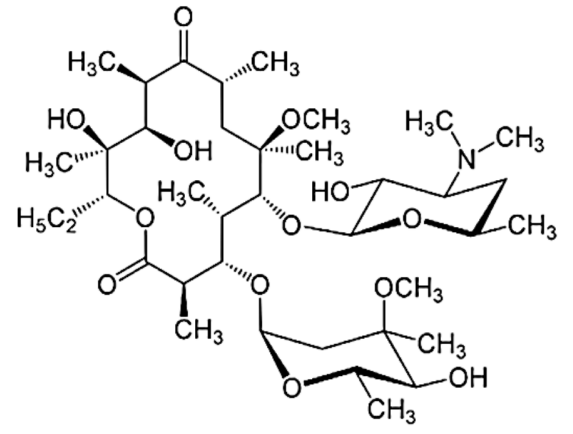

Figure 1. Structure of LVX (A) and CAM (B). 
solutions by adjusting the final concentrations to 10 , $25,50,75,100$, and $150 \mu \mathrm{g} / \mathrm{mL}$ of CAM and 5, 10, 20, 30, 40, and $50 \mu \mathrm{g} / \mathrm{mL}$ of LVX. Standard solutions were filtered using a $0.22 \mu \mathrm{m}$ membrane filter before running through the column.

\section{Preparation of sample solutions}

The pharmaceutical preparation containing 250 $\mathrm{mg}$ each of CAM and LVX was used for analysis. 20 tablets were weighed and the mean tablet weight was calculated. Then tablets were crushed in a mortar and pestle and powder equivalent to one tablet weight was dissolved in $0.1 \%$ acetic acid to prepare a solution having a concentration of $1000 \mu \mathrm{g} / \mathrm{mL}$ of both drugs. This solution was then centrifuged at $3000 \mathrm{~g}$ for $10 \mathrm{~min}$ to separate un-dissolved excipients. The supernatant was diluted with the HPLC mobile phase to prepare a combined sample solution with a final concentration of $50 \mu \mathrm{g} / \mathrm{mL}$.

\section{Chromatographic conditions}

Eclipse X DB C18 column $(5 \mu \mathrm{m}, 4.6 \times 250$ $\mathrm{mm}$ ) was used as a stationary phase, and monobasic potassium phosphate buffer $(0.035 \mathrm{M})$ : acetonitrile $(75: 25 \mathrm{v} / \mathrm{v}), \mathrm{pH} 4.5$ was used as an isocratic mobile phase. The mobile phase was filtered by vacuum filtration assembly using a $0.22 \mu \mathrm{m}$ nylon filter. $20 \mu \mathrm{L}$ of the sample was eluted at a flow rate of 1.0 $\mathrm{mL} / \mathrm{min}$ through the column kept at $40^{\circ} \mathrm{C}$ temperature and detected at $205 \mathrm{~nm}$ and $294 \mathrm{~nm}$.

\section{System suitability parameters}

System suitability parameters such as retention time $\left(t_{R}\right)$, tailing factor, capacity factor $\left(k^{\sim}\right)$, number of theoretical plates $(\mathrm{N})$, height equivalent to a theoretical plate (HETP) and reduced plate height were calculated from the chromatogram.

\section{Method validation}

The developed method was validated to ensure its reproducibility in order to achieve the desired results. Method validation parameters such as linearity, range, the limit of detection (LOD), the limit of quantification (LOQ), intra and inter-day trueness, and precision and robustness were calculated. Standard guidelines of the International Conference of Harmonization ( $\mathrm{ICH}$ ) were considered to validate the method (19).

\section{Linearity and range}

Linearity is the proficiency of an analytical method to produce results that are directly proportional to the analyte concentration in the sample. Working solutions (10-150 $\mu \mathrm{g} / \mathrm{mL})$ of CAM and (5-50 $\mu \mathrm{g} / \mathrm{mL}$ ) of LVX were analyzed in triplicates to plot a calibration curve. The linearity was calculated from the chromatogram and subsequently validated from the regression equation and correlation coefficient $\left(\mathrm{R}^{2}\right)$ (20). Linearity studies were used to derive the range.

\section{LOD and LOQ}

LOD is the minimum concentration of an analyte in the sample that can be detected with a certain level of confidence. LOQ is the minimum concentration of analyte that can be quantified with a given level of confidence. The mean slope (S) of the standard curves and standard deviation (SD) of the intercepts were analyzed statistically to estimate sensitivity parameters (21).

\section{Intra and inter-day trueness and precision}

Trueness and precision were calculated at different concentrations, i.e., $10,50,150 \mu \mathrm{g} / \mathrm{mL}$ of CAM and 5, 20, $50 \mu \mathrm{g} / \mathrm{mL}$ of LVX. Solutions were analyzed 4 times a day to calculate repeatability and reproducibility (intra-day trueness and precision) and once a day for 5 successive days, to calculate inter-day trueness and precision. Trueness was calculated as percentage recovery and precision was calculated as percentage relative standard deviation (\% RSD) (22).

\section{Robustness}

Robustness is the adeptness of the analytical method to withstand minor deliberate changes in the defined procedure and chromatographic conditions (23). Chromatographic conditions such as sample preparation, composition, and $\mathrm{pH}$ of the mobile phase, column temperature, and detection wavelengths were altered deliberately to observe their effect on percent recovery and to estimate the method's robustness.

\section{Application of the method to a pharmaceutical preparation}

Sample solutions were analyzed according to given chromatographic conditions. The analysis was carried out in triplicate and the percentage content of drugs in sample solutions was determined from the linear regression equation.

\section{RESULTS AND DISCUSSION}

\section{Method optimization}

The first step in developing an HPLC-DAD method is the selection of optimum absorption wavelengths. As per the literature, CAM and LVX 
show maximum absorption at the wavelength $\left(\lambda_{\max }\right)$ of $205 \mathrm{~nm}$ and $294 \mathrm{~nm}$, respectively $(24,25)$. Therefore, DAD detector was operated at $205 \mathrm{~nm}$ and $294 \mathrm{~nm}$ to quantify both drugs concurrently. Chromatographic results of CAM and LVX were investigated under various chromatographic conditions. Mobile phases of different compositions comprising methanol, acetonitrile, and monobasic potassium phosphate buffers were evaluated. The use of methanol and monobasic potassium phosphate combination as mobile phase resulted in peak splitting of CAM. However, the peak splitting disappeared and the peak shape improved by using a combination of acetonitrile and monobasic potassium phosphate buffer. Several combinations of monobasic potassi- um phosphate buffers and acetonitrile $(70: 30,75$ : 25 and $80: 20 \mathrm{v} / \mathrm{v}$ ) were studied to select the optimum combination. It was observed that the incremental concentration of monobasic potassium phosphate produced no significant effect on the retention time of CAM, but the retention time of LVX increased up to $11 \mathrm{~min}$ at a maximum concentration of monobasic potassium phosphate (20:80 v/v). Finally, after repeated analysis, $75: 25 v / v$ was selected as the most suitable concentration ratio, but still some effort was needed to increase the retention time of CAM beyond $4 \mathrm{~min}$. Therefore, the mobile phase polarity was enhanced by adding different acids such as diluted acetic acid, hydrochloric acid, and orthophosphoric acid. As consistent with the lit-
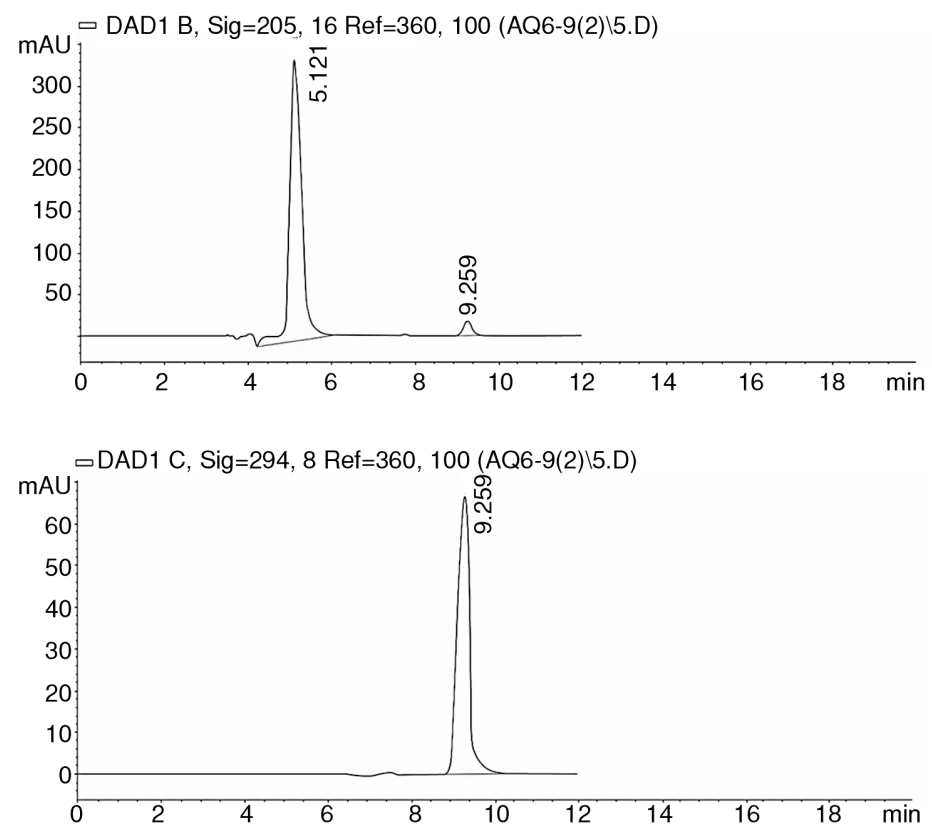

Figure 2. HPLC chromatogram of a mixed standard solution of CAM and LVX.

Table 1. System suitability parameters for determination of LVX and CAM.

\begin{tabular}{|c|c|c|c|c|}
\hline \multirow{2}{*}{ System suitability parameters } & \multirow{2}{*}{ Unit } & \multicolumn{2}{|c|}{ Values } & \multirow{2}{*}{ Reference values } \\
\hline & & CAM & LVX & \\
\hline Retention time $\left(\mathrm{T}_{\mathrm{R}}\right)$ & Min & 5.12 & 9.25 & $>4$ \\
\hline Capacity factor (k') & NA & 4.12 & 8.25 & $>2$ \\
\hline Tailing factor $(\mathrm{T})$ & NA & 0.97 & 1.02 & $\geq 2$ \\
\hline No. of theoretical plates $(\mathrm{N})$ & NA & 6819 & 22070 & $>2000$ \\
\hline Height equivalent to a theoretical plate (HETP) & $\mu \mathrm{m}$ & 36.66 & 11.33 & NA \\
\hline Reduced plate height & $\mu \mathrm{m}$ & 7.33 & 2.27 & NA \\
\hline
\end{tabular}



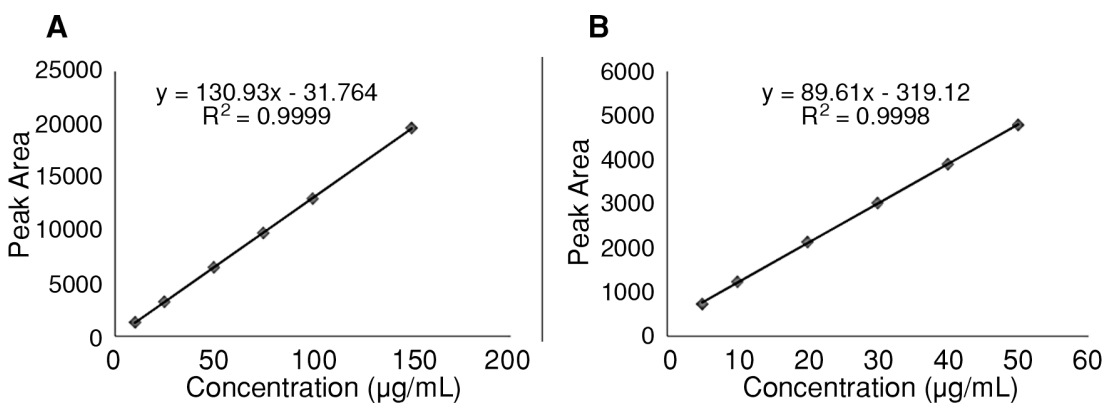

Figure 3. Standard curves of CAM (A) and LVX (B).

Table 2. Results of linearity, LOD, LOQ, and correlation coefficient of CAM and LVX.I

\begin{tabular}{|c|c|c|c|c|c|}
\hline \multicolumn{6}{|c|}{ CAM } \\
\hline $\begin{array}{l}\text { Sr. } \\
\text { no. }\end{array}$ & $\begin{array}{l}\text { Concentration } \\
(\mu \mathrm{g} / \mathrm{mL})\end{array}$ & $\begin{array}{c}\text { Linear regression } \\
\text { equation }\end{array}$ & Slope & Intercept & $\begin{array}{l}\text { Correlation coefficient } \\
\qquad\left(\mathrm{R}^{2}\right)\end{array}$ \\
\hline 1 & $10-150$ & $y=130.93 x-31.76$ & 130.93 & 31.76 & 0.9999 \\
\hline 2 & $10-150$ & $y=131.15 x-31.01$ & 131.15 & 31.01 & 0.9998 \\
\hline 3 & $10-150$ & $y=131.71 x-54.79$ & 131.71 & 54.79 & 0.9999 \\
\hline 4 & $10-150$ & $y=131.59 x-41.92$ & 131.59 & 41.92 & 0.9997 \\
\hline \multicolumn{6}{|c|}{ Mean slope $(S)=131.35$} \\
\hline \multicolumn{6}{|c|}{ Standard deviation of intercept $(\mathrm{SD})=53.55$} \\
\hline \multicolumn{6}{|c|}{$\mathrm{LOD}=3 \mathrm{SD} / \mathrm{S}=1.22 \mu \mathrm{g} / \mathrm{mL}$} \\
\hline \multicolumn{6}{|c|}{$\mathrm{LOQ}=10 \mathrm{SD} / \mathrm{S}=4.08 \mu \mathrm{g} / \mathrm{mL}$} \\
\hline \multicolumn{6}{|c|}{ LVX } \\
\hline $\begin{array}{l}\text { Sr. } \\
\text { no. }\end{array}$ & $\begin{array}{l}\text { Concentration } \\
(\mu \mathrm{g} / \mathrm{mL})\end{array}$ & $\begin{array}{l}\text { Linear regression } \\
\text { equation }\end{array}$ & Slope & Intercept & $\begin{array}{c}\text { Correlation coefficient } \\
\left(\mathrm{R}^{2}\right)\end{array}$ \\
\hline 1 & $5.0-50$ & $y=89.61 x+319.12$ & 89.61 & 319.12 & 0.9998 \\
\hline 2 & $5.0-50$ & $y=89.10 x+316.82$ & 89.10 & 316.82 & 0.9995 \\
\hline 3 & $5.0-50$ & $y=88.34 x+340.53$ & 88.34 & 340.53 & 0.9997 \\
\hline 4 & $5.0-50$ & $y=88.66 x+333.39$ & 88.66 & 333.39 & 0.9996 \\
\hline \multicolumn{6}{|c|}{ Mean slope $(\mathrm{S})=88.84$} \\
\hline \multicolumn{6}{|c|}{ Standard deviation of intercept $(\mathrm{SD})=23.44$} \\
\hline \multicolumn{6}{|c|}{$\mathrm{LOD}=3 \mathrm{SD} / \mathrm{S}=0.79 \mu \mathrm{g} / \mathrm{mL}$} \\
\hline \multicolumn{6}{|c|}{$\mathrm{LOQ}=10 \mathrm{SD} / \mathrm{S}=2.64 \mu \mathrm{g} / \mathrm{mL}$} \\
\hline
\end{tabular}

erature, an increase in retention time was observed by adding diluted acetic acid and hydrochloric acid, but several noisy peaks were visible. However, the addition of diluted orthophosphoric acid produced a stable baseline with a minimum of noise. Lotfipour et al. used a similar approach to increase the retention time by adding different acids in the mobile phase (26). Similarly, the $\mathrm{pH}$ of the mobile phase also plays a significant role in retention time, peak shape, and selectivity. The analysis was performed at various $\mathrm{pH}$ values to optimize the $\mathrm{pH}$; the optimum peak shape was achieved at $\mathrm{pH}$ 4.5. Mobile phase flow rate of $1 \mathrm{~mL} / \mathrm{min}$ produced satisfactory retention times of both drugs. Likewise, column temperature is another parameter that affects the retention time. As per literature, an increase in column temperature decreases the retention time (27). By performing analysis at various temperatures (20$45^{\circ} \mathrm{C}$ ), $40^{\circ} \mathrm{C}$ was selected as the most suitable temperature. Therefore, optimum chromatographic 
Table 3. Intra-day and inter-day precision and trueness of assay of CAM and LVX $(n=3)$

\begin{tabular}{|c|c|c|c|c|}
\hline \multicolumn{5}{|c|}{ CAM } \\
\hline \multirow{2}{*}{$\begin{array}{l}\text { Concentration } \\
(\mu \mathrm{g} / \mathrm{mL})\end{array}$} & \multicolumn{2}{|c|}{ Intra-day } & \multicolumn{2}{|c|}{ Inter-day } \\
\hline & Precision (\% RSD) & Trueness \pm SD & Precision (\% RSD) & Trueness \pm SD \\
\hline 10 & 0.64 & $101.87 \pm 0.31$ & 1.37 & $98.67 \pm 0.42$ \\
\hline 50 & 1.13 & $101.41 \pm 0.43$ & 0.85 & $101.47 \pm 0.36$ \\
\hline 150 & 0.31 & $98.49 \pm 0.21$ & 0.45 & $100.44 \pm 0.27$ \\
\hline \multicolumn{5}{|c|}{ LVX } \\
\hline \multirow{2}{*}{$\begin{array}{c}\text { Concentration } \\
(\mu \mathrm{g} / \mathrm{mL})\end{array}$} & \multicolumn{2}{|c|}{ Intra-day } & \multicolumn{2}{|c|}{ Inter-day } \\
\hline & Precision (\% RSD) & Trueness $\pm \mathrm{SD}$ & Precision (\% RSD) & Trueness $\pm \mathrm{SD}$ \\
\hline 5 & 1.31 & $98.87 \pm 0.39$ & 1.51 & $99.47 \pm 0.53$ \\
\hline 20 & 0.93 & $101.48 \pm 0.37$ & 1.22 & $99.45 \pm 0.43$ \\
\hline 50 & 0.69 & $99.26 \pm 0.28$ & 0.87 & $101.39 \pm 0.35$ \\
\hline
\end{tabular}

results were attained by using monobasic potassium phosphate buffer: acetonitrile $(75: 25 \mathrm{v} / \mathrm{v})$, $\mathrm{pH}$ adjusted to 4.5 with the help of diluted orthophosphoric acid, flowing at $1.0 \mathrm{~mL} / \mathrm{min}$ through the column maintained at $40^{\circ} \mathrm{C}$ temperature. Under optimum chromatographic conditions, retention times observed for CAM and LVX were 5.12 and $9.25 \mathrm{~min}$, respectively (Fig. 2). The developed method is comparable to the one developed previously by Vignaduzzo et al. for simultaneous quantification of meloxicam and pridinol mesylate by RP-HPLC-DAD (28).

\section{System suitability}

System suitability parameters along with reference values are given in Table 1. All parameters were found within the limits recommended by the Center for Drug Evaluation and Research (CDER), which supports the suitability of the system for analysis of both drugs (29).

\section{Method validation}

\section{Linearity and range}

Standard curves (concentration versus peak area) of CAM and LVX are shown in Figure 3A and $\mathrm{B}$, respectively. CAM showed a linear response within $10-150 \mu \mathrm{g} / \mathrm{mL}$ with Pearson's coefficient (R) value of 0.9999 . While LVX showed a linear response within $5-50 \mu \mathrm{g} / \mathrm{mL}$ with an R-value of 0.9998 . These values are in line with the specifications given by ICH guidelines (19).

\section{LOD and LOQ}

LOD and LOQ values of CAM and LVX are given in Table 2. In the case of CAM, the LOD and LOQ values were found to be $1.22 \mu \mathrm{g} / \mathrm{mL}$ and 4.08 $\mu \mathrm{g} / \mathrm{mL}$, respectively. For LVX, LOD and LOQ val- ues were $0.79 \mu \mathrm{g} / \mathrm{mL}$ and $2.64 \mu \mathrm{g} / \mathrm{mL}$, respectively. These results advocated the sensitivity of the analytical method in accordance with ICH guidelines (19).

\section{Intra and inter-day trueness and precision}

Results of trueness and precision for both drugs (Table 3) showed both intra and inter-day precision with \% RSD values less than $2 \%$. Trueness calculated as percent recovery for both drugs was in the range of $98-102 \%$.

\section{Robustness}

Results of recovery studies, retention time, and peak area after purposely varying the chromatographic conditions displayed very little variations in the results, thus confirming the robustness of the method.

\section{Application of the method to a pharmaceutical preparation}

The developed method was applied to the combined formulation (tablet) of CAM and LVX. Chromatograms obtained after triplicate analysis of sample solution showed comparable Gaussian peak and retention time for both drugs with standard solutions. The percent recovery calculated for CAM and LVX in the sample solution was $99.76 \pm 0.49 \%$ and $99.62 \pm 0.37 \%$, respectively. These results established the sensitivity, trueness, and reproducibility of the method for simultaneous quantification of CAM and LVX.

\section{CONCLUSION}

A validated RP-HPLC method has been successfully developed for the simultaneous determina- 
tion of CAM and LVX. All the system suitability parameters were consistent with the recommended values. The method has shown acceptable results for the quantification of both drugs in their combined formulation. In the future, this method can be used for the concurrent bio-analytical quantification of the aforementioned drugs in biological fluids.

\section{Conflicts of interest}

The authors declare no conflict of interest.

\section{REFERENCES}

1. Rao R.N., Nagaraju V.: J. Pharm. Biomed. Anal. 33, 335 (2003).

2. Gupta V., Jain A.D.K.J., Gill N., Guptan K.: Int. Res. J. Pharmaceut. Appl. Sci. 2, 17 (2012).

3. Swartz M.: J. Liq. Chromatogr. Rel. Technol. 33, 1130 (2010).

4. Grosa G., Del Grosso E., Russo R., Allegrone G.: J. Pharm. Biomed. Anal. 41, 798 (2006).

5. Klastersky J.: Am. J. Med. 80, 2 (1986).

6. Cheng A., Sheng W.-H., Liou J.-M., Wang H.P., Wu M.-S., et al.: J. Microbiol. Immunol. Infect. 48, 72 (2015).

7. Martin S.J., Pendland S.L., Chen C., Schreckenberger P., Danziger L.H.: Antimicrob. Agents Chemother. 40, 1419 (1996).

8. Fish D.N., Chow A.T.: Clin. Pharmacokinet. 32, 101 (1997).

9. Bauernfeind A.: J. Antimicrob. Chemother. 40, 639 (1997).

10. Davis R., Bryson H.M.: Drugs 47, 677 (1994).

11. Lacy M.K., Owens Jr R.C., Xu X., Nicolau D.P., Quintiliani R., Nightingale C.H.: Int. J. Antimicrob. Agents 10, 279 (1998).

12. Peters D.H., Clissold S.P.: Drugs 44, 117 (1992).
13. Abuga K.O., Chepkwony H.K., Roets E., Hoogmartens J.: J. Sep. Sci. 24, 849 (2001).

14. Devi M.L., Chandrasekhar K.: J. Pharm. Biomed. Anal. 50, 710 (2009).

15. Locatelli M., Ciavarella M.T., Paolino D., Celia C., Fiscarelli E., et al.: J. Chromatogr. A 1419, 58 (2015).

16. Celia C., Di Marzio L., Locatelli M., Ramundo P., D’Ambrosio F., Tartaglia A.: Separations 7, 29 (2020).

17. Merone G.M., Tartaglia A., Locatelli M., D’Ovidio C., Rosato E., et al.: Analytica 1, 44 (2020).

18. Shah P., Pandya T., Gohel M., Thakkar V.: J. Taibah Univ. Sci. 13, 146 (2019).

19. Guideline I.H.T.: Q2 (R1) 1, 1 (2005).

20. Colombo M., de Lima Melchiades G., Figueiró F., Battastini A.M.O., Teixeira H.F., Koester L.S.: J. Pharm. Biomed. Anal. 145, 831 (2017).

21. Vial J., Jardy A.: Anal. Chem. 71, 2672 (1999).

22. Karnes H.T., March C.: Pharm. Res. 10, 1420 (1993).

23. Hubert P., Nguyen-Huu J.-J., Boulanger B., Chapuzet E., Chiap P., et al.: J. Pharm. Biomed. Anal. 45, 70 (2007).

24. Amini H., Ahmadiani A.: J. Chromatogr. B 817, 193 (2005).

25. Maleque M., Hasan M.R., Hossen F., Safi S.: J. Pharm. Anal. 2, 454 (2012).

26. Lotfipour F., Valizadeh H., Hallaj-Nezhadi S., Milani M., Zakeri-Milani P.: Iran. J. Pharm. Res. 9, 27 (2010).

27. Baba Y., Yoza N., Ohashi S.: J. Chromatogr. A 348, 27 (1985).

28. Vignaduzzo S.E., Castellano P.M., Kaufman T.S.: J. Pharm. Biomed. Anal. 46, 219 (2008).

29. Jenke D.R.: J. Liq. Chromatogr. Relat. Technol. 19, 1873 (1996). 